\title{
Biocontrol of Botrytis cinerea by successful introduction of Pantoea ananatis in the grapevine phyllosphere
}

This article was published in the following Dove Press journal:

International Journal of Wine Research

3 December 2012

Number of times this article has been viewed

\author{
Florian Gasser' \\ Massimiliano Cardinale ${ }^{1}$ \\ Barbara Schildberger ${ }^{2}$ \\ Gabriele Berg' \\ 'Institute of Environmental \\ Biotechnology, Graz University of \\ Technology, Graz, Austria; ${ }^{2}$ Höhere \\ Bundesanstalt und Bundesamt für \\ Wein-und Obstbau, Klosterneuburg, \\ Austria
}

Background and aims: The fungus Botrytis cinerea is a common problem in viticulture and leads to serious losses in both yield and quality. The objective was to study the potential of the antagonist Pantoea ananatis BLBT1-08 for controlling this disease.

Methods: Pathogen suppression by Pantoea treatments was investigated in different field trials and in detached leaf assays. The mode of action was studied by confocal laser scanning microscopy of treated grape leaves and by in vitro assays.

Results: The introduction of $P$. ananatis BLBT1-08 in a 3-year field trial resulted in statistically significant reduction of disease symptoms. However, $B$. cinerea abundance, measured by quantitative real-time polymerase chain reaction of a $B$. cinerea specific gene, was not reduced when compared to non-treated, symptom-free leaves. A DsRed fluorescent protein labeled BLBT1-08 strain showed a high phyllosphere competence and competition on the leaf surface, but did not colonize the inner parts of plant tissue. Germination of B. cinerea was not inhibited by BLBT1-08 on the leaf, but mycelial growth and symptoms were suppressed without direct pathogen-antagonist contact. The antimicrobial activity was amino acid and temperature dependent.

Conclusion: P. ananatis BLBT1-08 is a competitive and promising biocontrol agent for the control of $B$. cinerea and is highly effective at reducing disease incidence.

Keywords: biological control, sustainable viticulture, antagonism

\section{Introduction}

Botrytis cinerea is an ascomycetous fungus that infects more than 200 different species of plants, including grape vine. ${ }^{1,2}$ Botrytis bunch rot, caused by $B$. cinerea, is a common, worldwide problem in viticulture. This disease can cause serious losses in both yield and quality. $B$. cinerea is difficult to control due to its ability to rapidly develop resistance, to survive on alternate host plants or in latent stages, and to infect via different mechanisms. ${ }^{3}$ Organic viticulture, in particular, is threatened by this disease, as existing control measures are often not sufficiently effective. ${ }^{4,5}$ Furthermore, the high amounts of copper associated with organic control methods lead to enrichment of this heavy metal in the soil, causing severe danger for groundwater, ecosystems, and human health. ${ }^{6}$

Biological control is a promising measure for handling problematic plant pathogens and for reducing negative environmental impacts. ${ }^{7,8}$ This form of control involves application of beneficial microorganisms, which promote plant growth, enhance plant systemic resistance, and/or antagonize plant pathogens. Mechanisms involved in microbial antagonism include synthesis of pathogen inhibiting compounds, parasitism, and competition for space and nutrients. ${ }^{7,9}$ However, plant competence is
Correspondence: Gabriele Berg Institute of Environmental Biotechnology, Graz University of Technology, Petersgasse 12, 8010 Graz, Austria Email gabriele.berg@tugraz.at 
also a key feature for consistent biological control activity. ${ }^{8,10}$ The development of effective and consistent biological control strategies for pathogens is linked to the specialized ecological behavior of the biocontrol agents (BCAs). Knowledge of their ability to colonize the plant and how they interact with the pathogen and with the host plant can help to minimize problems associated with biocontrol methods.

In a previous study, we analyzed the ecology of grapevineassociated microorganisms that show antagonistic activity towards $B$. cinerea in different phyllosphere habitats. ${ }^{11}$ A subsequent study revealed a higher abundance of isolates with antagonistic traits against Botrytis in samples from grape berries in an organically managed vineyard. ${ }^{12}$ One strain, Pantoea ananatis BLBT1-08, was isolated from organically managed grape berries. P. ananatis, formerly known as Erwinia ananatis, is a Gammaproteobacterium frequently found in association with aerial plant parts. ${ }^{13}$ Several properties were identified that enabled this bacterium to colonize leaves and fruits with high efficiency: production of the phytohormone indole acetic acid (IAA), pigments, homoserine lactones, and extracellular polysaccharides. ${ }^{13,14}$ P. ananatis showed promise as a BCA against fungal and bacterial pathogens, but so far no detailed studies about its mode of action are available. ${ }^{15,16}$

In contrast to $P$. agglomerans, which, while being an efficient BCA is also a frequent opportunistic human pathogen, ${ }^{17,18} P$. ananatis is associated with little or no risk. The species is grouped into risk group 1 (no risk for humans and environment $)^{19}$ and there is only one report about the occurrence of $P$. ananatis in a human infection. ${ }^{20}$ In the present study, the P. ananatis BLBT1-08 strain was selected for further studies based on: (1) its high antagonistic activity; (2) its safety level; and (3) the need to understand its mode of interaction.

The objective of the present work was to assess the efficacy of the $P$. ananatis BLBT1-08 strain in controlling gray mold in grapevines, to study its colonization patterns, and to elucidate the major mechanisms underlying its mode of action. We evaluated the strain in a 3-year field trial and also by using leaf and in vitro assays. Confocal laser scanning microscopy (CLSM) of a DsRed fluorescent protein-labeled strain of BLBT1-08, quantitative real-time polymerase chain reaction (PCR) of a $B$. cinerea specific gene, re-isolation, and physiological assays were performed to study the mode of action and colonization patterns on the leaf. We evaluated the reduction in disease incidence and severity due to a successful introduction of $P$. ananatis into the phyllosphere in a field trial as well as under controlled conditions. We also identified mechanisms involved in the biocontrol activity ad planta and in vitro.

\section{Materials and methods Microbial strains, culture conditions and plant material}

Pantoea ananatis BLBT1-08 was isolated from ripe healthy grape berries (Vitis vinifera L. cv. Sauvignon Blanc) in 2007 from an organically managed vineyard in Schlossberg, Styria, Austria ( $46^{\circ} 37^{\prime} \mathrm{N}, 15^{\circ} 28^{\prime} \mathrm{E}$; Fachschule für Weinbau und Kellerwirtschaft und Weingut Silberberg). The strain was identified by $16 \mathrm{~S}$ rRNA gene sequencing (European Molecular Biology Laboratory [EMBL] Nucleotide Sequence Database, accession number FR865900). If not stated otherwise, BLBT1-08 was cultivated in nutrient broth II or on nutrient agar II (Sifin, Berlin, Germany) at $30^{\circ} \mathrm{C}$.

The DsRed labeled derivate of BLBT1-08, Panred4, was cultivated on/in the same media supplemented with tetracycline at a concentration of $40 \mu \mathrm{g} \mathrm{mL}^{-1}$. B. cinerea Klosterneuburg (KNB) was isolated from grape berries in Klosterneuburg, Lower Austria, Austria (48 $18^{\prime} \mathrm{N}, 16^{\circ}$ $20^{\prime} \mathrm{E}$ ) in 2007, using a Botrytis selective medium prepared according to the methods of Edwards and Seddon, ${ }^{21}$ and then cultivated on potato extract dextrose agar (PDA) (Carl Roth $\mathrm{GmbH}+\mathrm{Co} . \mathrm{KG}$, Karlsruhe, Germany) at room temperature in the dark. ${ }^{20}$ The strain was identified morphologically and by sequencing the ITS region between $18 \mathrm{~S}$ and 28S rRNA gene (EMBL acc nr FR872755). Production of conidia was induced by incubating 1-week-old PDA cultures under $12 \mathrm{~h}$ light.

Cuttings from $V$. vinifera cv. Sauvignon Blanc were obtained from the Research Centre for Agriculture Haidegg, Department 10A in Graz, Austria and planted in $5 \mathrm{~L}$ pots containing standard compost soil (Gramoflor, Vechta, Germany) and 1\% v/v quartz sand (Quartzwerke, Melk, Austria). Light conditions for induction of conidia production of $B$. cinerea and for plant growth were provided by halogen bulb lamps (43 kLux at a distance of $60 \mathrm{~cm}$ ) at $22^{\circ} \mathrm{C}-24^{\circ} \mathrm{C}$.

\section{Field trials}

The BLBT1-08 strain was grown in a 2 L flask with $500 \mathrm{~mL}$ culture medium for 24 hours at $180 \mathrm{rpm}$ to a cell density of approximately $2 \times 10^{9}$ colony forming units (CFU) $\mathrm{mL}^{-1}$. Culture medium was removed by centrifugation at $4500 \times \mathrm{g}$ for $15 \mathrm{~min}$ and cell material was re-suspended in deionized water to a final volume of $5 \mathrm{~L}$ prior to application, yielding

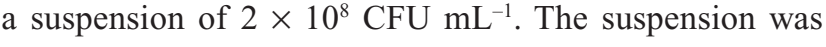
applied to grapes ( $V$. vinifera $\mathrm{cv}$. Rhein Riesling) growing in a trial vineyard located in Klosterneuburg, Lower Austria, Austria ( $48^{\circ} 18^{\prime} \mathrm{N}, 16^{\circ} 20^{\prime} \mathrm{E}$ ) by spraying the berry zone. Five liters of suspension were used for 40 grape plants and 
applied three times per growing season: at flower cap fall, 1 month after flower cap fall, and then 1 month prior to harvest. The effect on Botrytis infection was determined by visual rating of 100 grape bunches, which were classified according to the percentage of infected grape berries ( 0 : no infection, (1) $0.1 \%-5 \%$ infected berries, (2) $5.1 \%-10 \%$, (3) $10.1 \%-20 \%$, (4) $20.1 \%-40 \%$, (5) $40.1 \%-100 \%$ ). Infection index was calculated with the formula $\mathrm{Ii}=\Sigma\left(\mathrm{c}_{\mathrm{i}}\right.$ $\left.\times \mathrm{Bc}_{\mathrm{i}}\right) / \mathrm{B}$, where $\mathrm{I}_{\mathrm{i}}=$ infection index, $\mathrm{c}_{\mathrm{i}}=$ infection class, $\mathrm{Bc}_{\mathrm{i}}=$ number of bunches for the $\mathrm{c}_{\mathrm{i}}$ class and $\mathrm{B}=$ the overall number of rated bunches. Disease severity was the mean of infected grapes per bunch of rated bunches, whereas degree of infestation was the mean of percentage of infected grapes per bunch of bunches with a rating class $\geq 1$ only. Significance of differences between values of treated and untreated variants from original rating data was assessed by a two independent-sample Wilcoxon rank-sum test. Frequency of infestation was the percentage of infested bunches in 100 grape bunches.

\section{Detached leaf assays}

Three-week-old leaves from Sauvignon Blanc plantlets were gently washed under deionized water and the abaxial side was sprayed with suspensions of bacteria or $B$. cinerea conidia. Suspensions of BLBT1-08 (for quantitative realtime [qRT] PCR) or Panred4 (for confocal laser scanning microscopy) were obtained by centrifuging $1 \mathrm{~mL}$ of overnight liquid cultures for 10 minutes at $4500 \times \mathrm{g}$ and resuspending the pellet in sterile deionized water to an optical density of 0.1 at $600 \mathrm{~nm}$, corresponding to a bacterial concentration of $1.5 \times 10^{8} \mathrm{CFUs} \mathrm{mL}^{-1}$. Conidia of B. cinerea were washed from plates with $4 \mathrm{~mL}$ of Tween 80 $(10 \% \mathrm{w} / \mathrm{v}$; Carl Roth), centrifuged at $13000 \times \mathrm{g}$ for $2.5 \mathrm{~min}$, washed with sterile deionized water, and finally diluted to a concentration of $2 \times 10^{5}$ conidia $\mathrm{mL}^{-1}$. Concentration was assessed with a Thoma counting chamber $(0.1 \mathrm{~mm}$ depth; Marienfeld, Lauda-Koenigshofen, Germany) using a light microscope at a magnification of $200 \times$. Treated leaves were sprayed with $2 \mathrm{~mL}$ each of bacterial and conidia suspensions. Untreated control leaves were sprayed with $2 \mathrm{~mL}$ each of sterile water and conidia suspensions. Leaves were incubated with the abaxial side upwards in plastic boxes lined with moist filter paper at $22^{\circ} \mathrm{C}$ in the dark for 5 days. Areas of necrosis were assessed by counting and measuring spots of necrosis on each leaf. Leaves were either used immediately for confocal laser scanning microscopy or lyophilized at $8 \times 10^{-2}$ mbar and $-50^{\circ} \mathrm{C}$ for 3 days for subsequent DNA isolation.

\section{qRT-PCR}

DNA was isolated from $20 \mathrm{mg}$ of lyophilized and homogenized leaf material (obtained from detached leaf assays) using the FastDNA $^{\circledR}$ SPIN Kit for Soil and the FastPrep Instrument ${ }^{\circledR}$ (MP Biomedicals, Santa Ana, CA) according to the manufacturer's instructions. DNA was eluted in $50 \mu \mathrm{L}$ of DNase free water and used in 1:10 dilutions. The $B$. cinerea DNA was quantified using the primer pair CG11/CG12, which specifically binds to cutinase A (CutA) of B. cinerea. ${ }^{22}$ The qRT-PCR reaction was carried out in a Rotor Gene 6000 thermocycler (Corbett Research, Mortlake, Australia) using $0.4 \times$ SYBR $^{\circledR}$ Green I (Life Technologies, Carlsbad, $\mathrm{CA}$ ) in a $10 \mu \mathrm{L}$ reaction containing Taq-and $\mathrm{GO}^{\mathrm{TM}}$ Mastermix (MP Biomedicals), $0.5 \mathrm{pmol} / \mu \mathrm{L}$ of each primer, and $1 \mu \mathrm{L}$ of diluted template. One cycle consisted of $30 \mathrm{~s}$ denaturation at $95^{\circ} \mathrm{C}, 40 \mathrm{~s}$ annealing at $59^{\circ} \mathrm{C}$, and $30 \mathrm{~s}$ final elongation at $72^{\circ} \mathrm{C}$. Absolute quantification was based on a standard row of 1:5 dilutions of target fragments ranging from $1 \times 10^{4}$ to 80 copies $\mu \mathrm{L}^{-1}$. The target fragments were obtained by cloning the CG11/CG12 PCR product into pGEM $^{\circledR}$-Teasy Vector (Promega Corporation, Fitchburg, WI). The target fragment was amplified from this construct using the primers usp (5'-GTAAAACGACAACCAGT-3') and rsp (5'-CAGGAAACAGCTATGACC-3'). The quantification limit was determined at 80 copies $\mu 1^{-1}$, leading to an experimental quantification limit of $2 \times 10^{6}$ copies $\mathrm{g}^{-1}$ dry weight. $\mathrm{Ct}$ values of nontemplate controls were always higher than $\mathrm{Ct}$ values from the standard solutions containing 80 copies $\mu \mathrm{L}^{-1}$. The standard curve was linear in the range used $\left(\mathrm{R}^{2} \geq 0.986\right)$. Efficiency calculated from the slope of the standard curve was between 1.12 and 1.23. Amplification efficiencies were calculated from the slope of the exponential phase of the fluorescence history of each sample using the Rotor Gene thermocycler software and were between 1.84 and 2.04.

\section{Physiological assays}

Production of C4-C6 acyl homoserine-lactones (AHLs) was tested by a plate assay described by McClean et al. ${ }^{23}$ The test strain was cross-streaked against the reporter strain Chromobacterium violaceum CV026, an AHL deficient mutant, on nutrient agar II (Sifin). Development of purple color, which indicated violacein production by $C$. violaceum, was evaluated after 24 hours' incubation at $30^{\circ} \mathrm{C}$. The ability to synthesize indole-3-acetic acid (IAA) was tested by a colorimetric assay in liquid culture according to Sarwar and Kremer. ${ }^{24}$ Chitinase and $\alpha$-glucanase activity were tested on minimal medium. ${ }^{18,26}$ Clearing zones or blue haloes were detected 5 days after incubation at $20^{\circ} \mathrm{C}$. Production of 
volatile compounds (VOCs) with activity against $B$. cinerea was tested using two-compartment split plates (Sarstedt AG and Co, Nümbrecht, Germany). Agar discs grown with $B$. cinerea mycelium were set on one half of the plate containing PDA. On the other half, a suspension of the test strain was streaked in a defined area onto nutrient agar II (Sifin). The plates were sealed with Parafilm (Pechiney Plastic Packaging Company, Chicago, IL) and incubated for 4 days at $18^{\circ} \mathrm{C}$. The diameters of fungal colonies were measured and compared to a control without the test strain. The test was considered positive if the difference in diameters between test strain and control was $<0.05$ based on a Student's $t$-test. All physiological tests were replicated as described in the Statistics section statistic with strain BLBT1-08.

\section{Antibiosis tests}

Inhibition of $B$. cinerea KNB mycelial growth on rich medium was tested on PDA (Roth) at $22^{\circ} \mathrm{C}$. Agar discs grown with mycelia of $B$. cinerea were placed on the centre of a plate and the test strain was streaked out radially to these. The impact of amino acids on the inhibition of $B$. cinerea growth by $P$. ananatis was tested on synthetic low-nutrient agar (SNA) at $22^{\circ} \mathrm{C} .{ }^{26}$ Fungal mycelia were inoculated on the center of the plates, as described above. Cell material of strain BLBT1-08 plated overnight at $30^{\circ} \mathrm{C}$ was transferred to the minimal medium by stamping with an inoculation loop. The influence of $P$. ananatis on growth of Escherichia coli MG1655 was assessed by plating out dilutions of $E$. coli cultures grown overnight in nutrient broth on minimal medium according to Winkelmann et al. ${ }^{27}$ Cell material of $P$. ananatis was inoculated as described above. If required, amino acids or casamino acids were supplemented at a concentration of $5 \mathrm{mM}$ or $0.2 \%$, respectively, prior to autoclaving. Casaminoacids were obtained from Bacto (Hamburg, Germany) and single amino acids were 'for biochemistry' grade and from Merck KGaA (Darmstadt, Germany). Plates of B. cinerea and E. coli were incubated at room temperature for 3 and 5 days, respectively, and then the radius of the inhibition zone was measured in each plate. The significance of differences between the sizes of inhibition zones was calculated with the Scheffe procedure at a level of significance of 0.001 using PASW Statistics (v 18; IBM, Armonk, NY).

\section{Construction of a DsRed labeled derivate of $P$. ananatis BLBTI-08}

P. ananatis BLBT1-08 was transformed by electroporation with plasmid pME6031-DsRed2, carrying a gene for production of a red fluorescence protein, according to the procedure described by Zachow et al. ${ }^{10}$ The resulting transformant, named Panred4, was resistant to tetracycline and showed a red fluorescent signal under the microscope after cultivation on both selective and nonselective media for 4 days at room temperature. Box PCR genomic fingerprints, according to Rademaker and De Bruijn, were performed using colony PCR according to the protocol of Berg et al. ${ }^{28,29}$ The obtained fingerprints were identical to those from BLBT1-08. Physiological traits, in vitro antimicrobial activity, and biocontrol activity in detached leaf assays were identical to the wild type.

\section{Re-isolation of $P$. ananatis Panred4 from leaves}

Leaves were inoculated with Panred4 as described above and incubated for 5 days. Uninoculated leaves (sprayed with water instead of bacterial suspension) served as a control. Leaves were rinsed in bags containing $25 \mathrm{~mL}$ phosphate buffered salts + Tween $\left(8 \mathrm{~g} \mathrm{NaCl}, 1.42 \mathrm{~g} \mathrm{Na}_{2} \mathrm{HPO}_{4}, 0.2 \mathrm{~g} \mathrm{KCl}, 0.24 \mathrm{~g}\right.$ $\mathrm{KH}_{2} \mathrm{PO}_{4}$, all per liter; $0.05 \% \mathrm{w} / \mathrm{v}$ Tween 80; $\mathrm{pH}$ 7.4) for $90 \mathrm{~s}$ using a BagMixer ${ }^{\circledR}$ (INTERSCIENCE, St Nom la Bretêche, France) to remove the microorganisms. Serial dilutions of the bag contents were plated onto R2A Agar (Roth) containing $40 \mu \mathrm{g} \mathrm{mL} \mathrm{m}^{-1}$ tetracycline (Roth) and onto R2A agar (Roth). CFUs were counted after incubation overnight at $30^{\circ} \mathrm{C}$.

\section{Confocal laser scanning microscopy (CLSM)}

Material from the interveinal area was cut from grapevine leaves with a sterile scalpel. Microscopy specimens were mounted with Slow Fade ${ }^{\circledR}$ Gold antifade reagent (Life Technologies) and DAPI (4', 6-diamidino-2-phenylindole) in order to stain conidia and hyphae. Staining of conidia with DAPI led to only a faint signal in most cases, so localization of conidia was assessed with bright field and then marked in the image. Specimens were observed with a TCS SPE confocal microscope (Leica Microsystems, Wetzlar, Germany). DsRed was excited with a $532 \mathrm{~nm}$ laser light and the emitted fluorescent light was detected in the range 550-620 nm. Autofluorescence of plant tissue was observed at 420-500 nm when the specimen was excited with a $405 \mathrm{~nm}$ laser light. Confocal stacks were generated with a Z-step size of $0.17 \mu \mathrm{m}$. Three-dimensional models, based on spots and isosurfaces, were created with the Imaris 7.3 software (Bitplane, Zürich, Switzerland). Figures were assembled in Adobe Photoshop CS3, version 10.0.1 (Adobe Systems Incorporated, San Jose, CA). 


\section{Germination assays}

One hundred $\mu \mathrm{L}$ of conidia suspensions $\left(2 \times 10^{5}\right.$ conidia $\mathrm{mL}^{-1}$ counted in a Thoma counting chamber with $0.1 \mathrm{~mm}$ depth) were plated on PDA (Roth), SNA, and SNA with $0.2 \%$ casamino acids. The test strains were streaked on the plates and incubated for two to three days at room temperature. Germination of conidia in the vicinity of $P$. ananatis colonies was examined with a stereomicroscope $(16 \times$ and $40 \times$ magnification).

\section{Statistics}

In vitro assays were performed using four independent replicates and repeated at least two times. Leaf assays included six replicates and were repeated three times. For qRT-PCR, each sample was analyzed in two independent runs each, in four independent replicates. All results were statistically analyzed by ANOVA (analysis of variance) using SPSS version 10.0 for Windows. If ANOVA showed statistical significance, individual means were then compared using Tukey's pairwise comparison.

\section{Results}

\section{Application of $P$. ananatis reduced $B$. cinerea infection in field trials}

The efficacy of $P$. ananatis BLBT1-08 against $B$. cinerea infection was evaluated in a 3-year field trial. Suspensions of BLBT1-08 were applied by spraying the berry zone of grape plants. In all three years, infection index and disease severity were statistically significantly reduced $(P<0.005)$ in comparison to a non-treated control (Table 1). The proportion of infected grape bunches (frequency of infestation) was also lower in the BLBT1-08 treatments in all 3 years. The degree of infestation among infested grape bunches did not differ significantly from the control. In 2008, the difference in the degree of infestation among infested grape bunches was highest, with a significance of $P=0.08$, but this was considered not statistically significant. The infection index and disease severity of treated plants and control were lower in 2008 than in 2009 and 2010. Within each season, the infection index and disease severity from treated and nontreated grapes increased with the ripening state of the grape berries (data not shown).

\section{Inhibition of $B$. cinerea infection by $P$. ananatis BLBTI -08 in leaf assays}

The efficacy of BLBT1-08 in decreasing infection incidence under controlled conditions was verified using detached leaf assays. Detached grapevine leaves were sprayed with suspensions of BLBT1-08 and conidia of $B$. cinerea (treated) or with water and suspensions of conidia (untreated control). Within all leaf assays, treated leaves showed no symptoms of infection after 5 days of incubation (Figure 1). Among untreated controls, 13 out of 18 leaves showed necrosis as a symptom of $B$. cinerea infection. $B$. cinerea was successfully re-isolated from these leaves (data not shown). The extent of $B$. cinerea infection was measured by quantitative PCR to determine the copy number of the CutA gene. Areas of necrosis correlated with cutinase gene copy number in a linear manner $\left(\mathrm{R}^{2}=0.835\right)$ within symptomatic leaves. No statistically significant difference was noted in cutinase gene copy number between treated and untreated, symptom-free leaves $(P=0.335)$. Leaves sprayed with BLBT1-08 alone did not develop any symptoms.

\section{Physiological traits with relevance for biocontrol}

The mechanisms by which BLBT1-08 reduces $B$. cinerea infection incidence were explored using in vitro tests. P. ananatis BLBT1-08 was able to produce the plant growth hormone indole acetic acid (IAA) at a concentration of 20-30 $\mu \mathrm{g} \mathrm{mL}^{-1}$ in the cell-free supernatant when grown in a tryptophan-amended liquid medium. It also produced at least one type of quorum sensing autoinducer that stimulated violacein biosynthesis in an autoinducer-negative mutant of

Table I Visual rating of Botrytis infection of Pantoea ananatis BLBTI-08 treated grapes in a 3-year field trial

\begin{tabular}{|c|c|c|c|c|c|c|}
\hline \multirow[t]{2}{*}{ Effect/year } & \multicolumn{2}{|l|}{2008} & \multicolumn{2}{|l|}{2009} & \multicolumn{2}{|l|}{2010} \\
\hline & Control & Treated $^{\dagger}$ & Control & Treated $^{\dagger}$ & Control & Treated $^{\dagger}$ \\
\hline Infection index & 0.56 & $0.27 *$ & 2.48 & I.7I* & 2.62 & $1.90 *$ \\
\hline Disease severity & 3.24 & $1.00 *$ & 26.6 & $17.4^{*}$ & 27.4 & $18.6 *$ \\
\hline Infestation (\%) $)^{\ddagger}$ & II.3 & 7.2 & 34.5 & 29.4 & 33.4 & 28.2 \\
\hline Frequency of infestation (\%) & 29 & 17 & 77 & 59 & 82 & 66 \\
\hline
\end{tabular}

Notes: Percentage of Botrytis-infected grape berries in 100 grape bunches was visually assessed I week prior to harvest, and infection index, degree of infestation, and frequency of infestation were calculated. Suspensions of $P$. ananatis BLBTI-08 were sprayed three times in the period between cap-fall and I month prior to harvest for each year. 'Significance of differences of infection index and degree of infestation between treated and control samples is indicated by an asterisk ( $* P<0.005)$; ${ }^{\ddagger}$ degree of infestation was calculated as the mean of infestation from infested bunches only. 


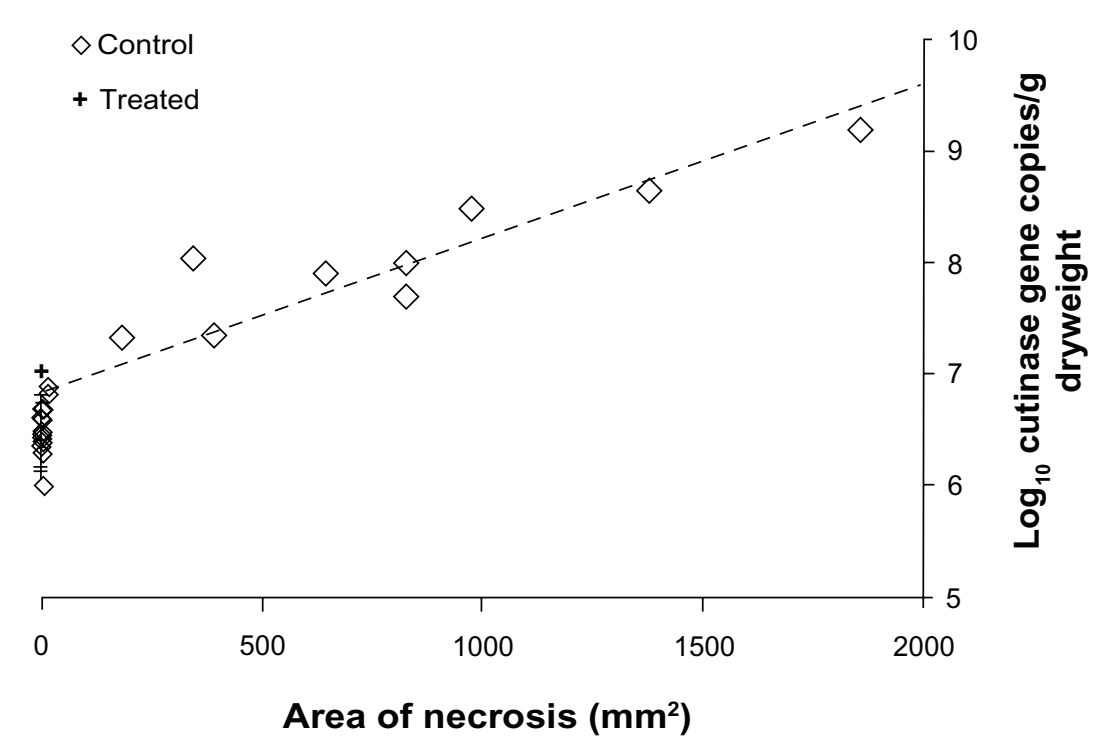

Figure I Inhibition of Botrytis-infection of detached leaves by Pantoea ananatis BLBTI-08.

Notes: Grapevine leaves were sprayed with suspensions of $P$. ananatis and B. cinerea conidia (treated) or with water and conidia (control). Area of necrosis was measured in symptomatic leaves and copy number of cutinase A gene was determined by qRT-PCR. The dotted line represents the least squares line, calculated from data from symptomatic leaves.

Chromobacterium violaceum. No production of the fungal cell wall degrading enzymes, chitinase and glucanase, was observed on minimal medium. Overall, P. ananatis BLBT108 was not able to inhibit growth of $B$. cinerea by production of volatile compounds.

\section{In vitro antimicrobial activity of $P$. ananatis BLBTI-08}

$P$. ananatis reduced growth of $B$. cinerea mycelium on nutrient-rich medium such as potato dextrose agar. When $P$. ananatis was streaked radially on the plate, an inhibition zone was formed at the outer part of the plate (Figure 2A). This inhibition was strongest when plates were incubated at $18^{\circ} \mathrm{C}$ and $12^{\circ} \mathrm{C}$. At higher temperatures $\left(20^{\circ} \mathrm{C}\right.$ and $\left.25^{\circ} \mathrm{C}\right)$, the inhibitory effect of BLBT1-08 was lower, but still evident. Growth of B. cinerea KNB was inhibited at $30^{\circ} \mathrm{C}$. A clear inhibition zone was formed in dual culture with BLBT1-08 on SNA at all temperatures tested (Figure 2B). Addition of casamino acids reduced the size of the inhibition zone significantly (Figure 2C). Leucine, isoleucine, methionine, tryptophan, threonine, and ornithine mitigated inhibition completely or to a level comparable with or lower than that observed with casamino acids (Figure 2D). Most of the other amino acids tested reduced the inhibition zone, but not to as great an extent as casamino acids. Only tyrosine, lysine, and arginine had no effect on the size of the inhibition zone (Table 2; Figure 2E). BLBT1-08 formed a clear inhibition zone with a diameter of $14 \pm 2 \mathrm{~mm}$ on bacterial lawns of
E. coli MG1655 on minimal agar plates (Figure 2F), which was also inhibited by addition of casamino acids (Figure $2 \mathrm{G}$ ). The inhibition zone was also absent in medium containing the amino acids isoleucine, methionine, or threonine (Table 2 and Figure 2H). Glutamine and ornithine significantly reduced the size of the inhibition zone, whereas other amino acids tested did not affect it (Figure 2I). Interestingly alanine, tyrosine, and lysine led to larger inhibition zones than observed in minimal medium without amino acids (Table 2).

\section{Colonization of grapevine leaves by $P$. ananatis Panred 4}

The colonization behavior of $P$. ananatis was investigated by confocal laser scanning microscopy observation of the DsRed-labeled strain $P$. ananatis Panred4. Re-isolation experiments were also conducted in order to quantify colonization efficacy. Five days after spraying leaves with bacterial suspensions with an optical density of 0.1 , Panred4 was re-isolated on tetracycline-containing plates in a quantity of $\log _{10} 4.98 \pm 0.28 \mathrm{CFU} \mathrm{g}^{-1}$ fresh weight. All colonies growing on tetracycline-containing plates had the same appearance and resembled Panred4 morphologically. No tetracycline resistant bacteria were isolated from leaves not inoculated with Panred4. The total number of bacteria isolated from inoculated leaves was $\log _{10} 6.97 \pm 0.25 \mathrm{CFU} \mathrm{g}^{-1}$ fresh weight. The number of total bacteria isolated from uninoculated leaves was slightly but not significantly lower than that from inoculated leaves $(6.77 \pm 0.29 ; P=0.099)$. 

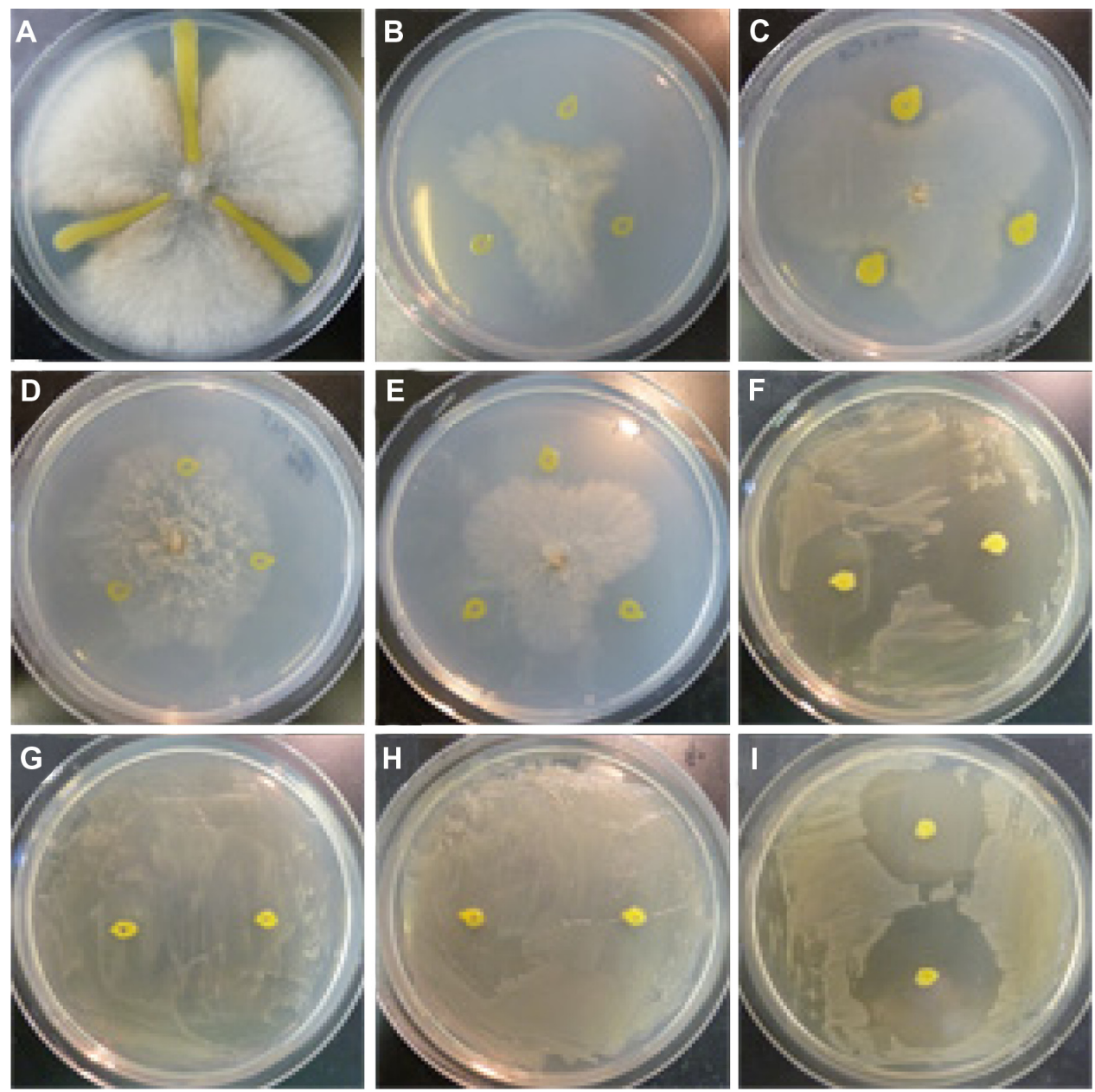

Figure 2 In vitro antimicrobial activity of Pantoea ananatis BLBTI-08 against Botrytis cinerea and Escherichia coli under different conditions.

Notes: P. ananatis and B. cinerea on potato dextrose agar (A); synthetic low-nutrient agar (B); SNA and 0.2\% casamino acids (C); SNA and 5 mM methionine (D); SNA and $5 \mathrm{mM}$ tyrosine (E); P. ananatis and $E$. coli on minimal medium (F); minimal medium and $0.2 \%$ casamino acids (G); minimal medium and $5 \mathrm{mM}$ threonine $(\mathbf{H})$; minimal medium and $5 \mathrm{mM}$ serine (I). PDA was incubated at $18^{\circ} \mathrm{C}$; all other plates were incubated at room temperature.

Abbreviations: SNA, synthetic low-nutrient agar; PDA, potato extract dextrose agar.

Confocal laser scanning microscopy (CLSM) revealed a dense colonization of the leaf surface by Panred4. Cells of Panred4 were scattered as single cells or micro-colonies on the uppermost layer of the abaxial surface (Figure 3A-D) and also colonized trichomes (Figure 3E). Three-dimensional rendering of the images revealed localization of single cells along epidermal cell wall junctions (Figures $3 \mathrm{H}$ and $\mathrm{I}$ ). Panred4 was not detected in the leaf endosphere. No signal for DsRed was detected in uninoculated leaves.

\section{Interaction of $P$. ananatis with $B$. cinerea ad planta}

The potential interaction of $P$. ananatis with $B$. cinerea was assessed ad planta by spraying leaves with both microorganisms, followed by observation with CLSM. The presence of conidia or germinating conidia on the leaves did not alter the colonization pattern of $P$. ananatis Panred4. Panred4 did not co-localize with, or adhere to, B. cinerea conidia or germ tubes on grapevine leaves (Figure $3 \mathrm{~F}$ and $\mathrm{G}$ ). Germinating conidia were found after 1, 2, and 3 days in both treated and non-treated leaves, and at comparable densities. Plate assays carried out on potato dextrose agar, SNA, and SNA with $0.2 \%$ casamino acids indicated no suppression of germination of $B$. cinerea conidia by either P. ananatis BLBT1-08 or Panred4. Germination of conidia and the development of the first hyphae occurred evenly throughout the plates and also in the vicinity of $P$. ananatis colonies on all media tested. Mycelial growth continued on PDA and SNA with casamino acids, but further growth was suppressed in the vicinity of $P$. ananatis colonies on SNA (data not shown).

\section{Discussion}

The 3-year field trial and the detached leaf assays demonstrated efficient control of $B$. cinerea by the introduced $P$. ananatis 
Table 2 Inhibition of Botrytis cinerea and Escherichia coli by Pantoea ananatis BLBTI-08 in the presence of casamino acids or single amino acids ${ }^{\dagger}$

\begin{tabular}{|c|c|}
\hline Medium & \\
\hline \multicolumn{2}{|c|}{ P. ananatis versus B. cinerea } \\
\hline $\mathrm{SNA}^{\ddagger}$ & $7.2^{\mathrm{b}-\mathrm{d}}$ \\
\hline $\mathrm{CA}^{*}$ & $1.2^{\mathrm{a}}$ \\
\hline Gly & $4.2^{\mathrm{a}-\mathrm{c}}$ \\
\hline Ala & $2.3^{\mathrm{a}, \mathrm{b}}$ \\
\hline Val & $3.3^{\mathrm{a}, \mathrm{b}}$ \\
\hline Leu & $0.5^{\mathrm{a}}$ \\
\hline Ile & $1.6^{\mathrm{a}}$ \\
\hline Met & $0.0^{\mathrm{a}}$ \\
\hline Pro & $3.4^{\mathrm{a}, \mathrm{b}}$ \\
\hline Phe & $3.2^{\mathrm{a}, \mathrm{b}}$ \\
\hline Trp & $0.2^{\mathrm{a}}$ \\
\hline Ser & $3.8^{\mathrm{a}-\mathrm{c}}$ \\
\hline Thr & $0.0^{\mathrm{a}}$ \\
\hline Asn & $3.8^{\mathrm{a}-\mathrm{c}}$ \\
\hline Gln & $4.3^{a-c}$ \\
\hline Tyr & $7.0^{b-d}$ \\
\hline Cys & $2.6^{\mathrm{a}, \mathrm{b}}$ \\
\hline Lys & $8.7^{\mathrm{b}-\mathrm{d}}$ \\
\hline Arg & $9.3^{b-d}$ \\
\hline His & 4. $1^{a-c}$ \\
\hline Orn & $0.1^{\mathrm{a}}$ \\
\hline Asp & n.d $d^{\pi}$ \\
\hline Glu & n.d $d^{\pi}$ \\
\hline \multicolumn{2}{|c|}{$P$. ananatis versus $E$. coli } \\
\hline $\mathrm{MM}^{\ddagger}$ & $13.9^{\mathrm{b}, \mathrm{c}}$ \\
\hline $\mathrm{CA}^{*}$ & $0.0^{\mathrm{a}}$ \\
\hline Gly & $10.6^{\mathrm{b}, \mathrm{c}}$ \\
\hline Ala & $15.5^{c}$ \\
\hline Val & n.d. ${ }^{\S}$ \\
\hline Leu & $12.8^{\mathrm{b}, \mathrm{c}}$ \\
\hline Ile & $0.0^{\mathrm{a}}$ \\
\hline Met & $0.0^{\mathrm{a}}$ \\
\hline Pro & $12.4^{\mathrm{b}, \mathrm{c}}$ \\
\hline Phe & $10.4^{\mathrm{b}, \mathrm{c}}$ \\
\hline Trp & $13.4^{\mathrm{b}, \mathrm{c}}$ \\
\hline Ser & $14 . I^{b, c}$ \\
\hline Thr & $0.0^{\mathrm{a}}$ \\
\hline Asn & $14.1 b^{c}$ \\
\hline Gln & $9.25^{b}$ \\
\hline Tyr & $15.4^{c}$ \\
\hline Cys & $10.6^{\mathrm{b}, \mathrm{c}}$ \\
\hline Lys & $15.8^{c}$ \\
\hline Arg & $10.9^{b, c}$ \\
\hline $\mathrm{His}$ & $14.6^{\mathrm{b}, \mathrm{c}}$ \\
\hline Orn & $9.2^{\mathrm{b}}$ \\
\hline Asp & $13.8^{b, c}$ \\
\hline Glu & $13.9^{\mathrm{b}, \mathrm{c}}$ \\
\hline
\end{tabular}

Notes: ${ }^{+}$Radius of inhibition zone formed by $P$. ananatis was measured $(\mathrm{mm})$. Amino acids were added in a concentration of $5 \mathrm{mM}$. ${ }^{\mathrm{a}-c}$ Significant differences calculated with the Scheffe procedure $(\alpha=0.00 \mathrm{I})$. Items sharing the same letter are not significantly different. ‡Synthetic low-nutrient agar (SNA) or minimal medium (MM) without additional amino acids. *Casamino acids, $0.2 \%$. "Influence of aspartic acid and glutamic acid was not determined because lowered $\mathrm{pH}$ prevented polymerization of agar. Influence of valine was not assessed because growth of E. coli MGI655 is inhibited by valine in minimal medium.
BLBT1-08. Mycelial growth was inhibited in an amino acid and temperature dependent manner, but germination of $B$. cinerea conidia was not affected by the presence of $P$. ananatis.

The most surprising result was that equal amounts of B. cinerea DNA were detected in Pantoea-treated and untreated but symptom-free leaves. This indicates that the strain may act by preventing penetration of $B$. cinerea. Bonaterra et al found a direct interaction of a strain of $P$. agglomerans on $B$. cinerea and inhibition of germination of conidia. ${ }^{30}$ Correlation of B. cinerea DNA content and the area of necrosis in infected leaves showed the soundness of the method used. In this study, no evidence for inhibition of germination of conidia was found under the conditions applied.

Data from plate assays showed that addition of certain amino acids prevented the antimicrobial activity towards $B$. cinerea. Interestingly, more than one amino acid was able to prevent the inhibitory effects of $P$. ananatis when added individually to the medium: methionine, threonine, tryptophan, leucine, and ornithine. Two of these amino acids - methionine and threonine - also prevented the inhibition of $E$. coli growth on minimal medium. This result may reflect the finding that some strains of $P$. agglomerans are known to produce antibiotics that can be reversed by amino acids. For example, P. agglomerans EH318 produces the histidine reversible pantocin $\mathrm{A}$, as well as the arginine reversible pantocin $B{ }^{31,32}$ Similarly, A351, a peptide antibiotic isolated from P. agglomerans Eh351 is arginine reversible, and other histidine reversible substances, namely mccEh 252 from strain Eh252 and herbicolin O from strain C9-1, are known. ${ }^{33,34}$ Herbicolin A and B are peptides produced by P. ananatis A111 (formerly known as Erwinia herbicola A111) that are inhibitory to fungi, but the effect of amino acids on their function has not been investigated. 27,35 Weak acids like acetate are known to inhibit growth of $E$. coli in a multifactorial manner. ${ }^{36,37}$ This inhibition can be prevented by addition of methionine and glycine. ${ }^{38}$ Growth inhibition caused by other stress factors like high temperatures can also be prohibited by methionine. ${ }^{39}$ Because we observed restoration of $B$. cinerea and $E$. coli growth by addition of more than one individual amino acid, we exclude the possibility that the action of $P$. ananatis BLBT1-08 is exclusively a direct effect on amino acid biosynthesis pathways. Pantoea ananatis BLBT1-08 also inhibited growth of $B$. cinerea on rich medium, suggesting further mechanisms that are independent of the presence of amino acids.

The present study revealed no evidence for pathogenic effects of $P$. ananatis BLBT1-08 in grapevines. Leaves treated with BLBT1-08 alone did not develop any symptoms even 

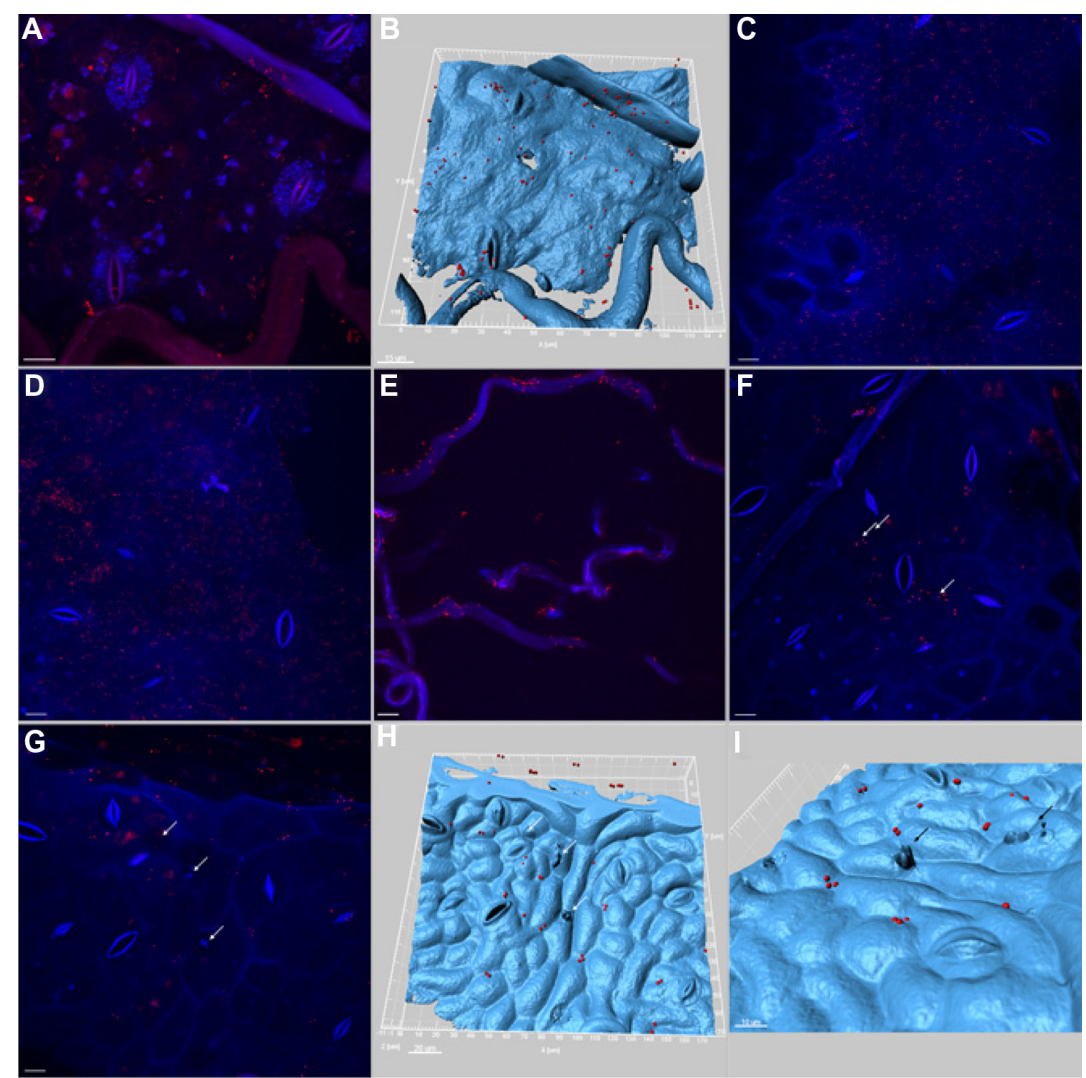

Figure 3 Confocal laser scanning microscopy of Pantoea ananatis on grapevine leaves.

Notes: Strain BLBTI-08 was transformed with a DsRed-carrying plasmid to enable fluorescence microscopy. Leaves were sprayed with the transformed strain (Panred4) (A-E) or with Panred4 and Botrytis conidia (F-I). Red signal represents fluorescence of DsRed. Three-dimensional models were created with Imaris software (Bitplane, Zürich, Switzerland) (B, $\mathbf{H}$ and I). Scale bars are $10 \mu \mathrm{m}$, except $(\mathbf{H}), 20 \mu \mathrm{m}$. Arrows indicate localization of Botrytis conidia.

after prolonged incubation (data not shown). Some strains of $P$. ananatis have been associated with plant diseases (for example, in melons, onions, and pineapples). ${ }^{13,40}$ Conversely, P. ananatis is frequently isolated from asymptomatic plants and elicits antagonistic traits against plant pathogenic bacteria and fungi, thereby conveying protection to their host plants. ${ }^{41}$ The plant-microbe balance and the individual strain-specific effects might explain these contrasting reports. Consideration of strain-specific traits is important for the characterization of biocontrol strains as well as for pathogens: each strain of one species can have its specific antagonistic and pathogenic properties and can show different biocontrol effects in the field. ${ }^{17,18,26}$ Strain-specific effects have to be considered in the development, biosafety assessment, and registration procedure for BCAs.

Biocontrol activity of $P$. ananatis BLBT1-08 ad planta has a multifactorial nature. One important prerequisite for an effective BCA is its ability to colonize plant tissues. Re-isolation data and confocal laser scanning microscopy in the present study revealed efficient colonization of grapevine leaves by $P$. ananatis. Bacterial cells were distributed singularly and in micro-colonies throughout the leaf surface. Similar observations were reported for P. agglomerans on leaves of maize and bean. ${ }^{42}$ By occupying possible infection sites, P. ananatis BLBT1-08 lowers the possibility of B. cinerea infection, as was observed in this study. However in oligotrophic environments such as leaf surfaces, production of compounds that induce amino acid dependency in competing microorganisms may be advantageous for $P$. ananatis.

This study confirms that $P$. ananatis strain BLBT1-08 could be an efficient agent for controlling the plant pathogen B. cinerea, as determined by leaf assays and in a 3-year field trial. We suggest that its mode of action is multifactorial as BLBT1-08 has good plant colonizing traits but also shows antimicrobial activity in vitro.

\section{Acknowledgments}

We thank Wolfgang Renner from the Research Centre for Agriculture Haidegg (Graz, Austria) for providing grapevine cuttings and for support in cultivation of grapevine plants. We also thank BASF (Ludwigshafen, Germany) for partial funding. 


\section{Disclosure}

The authors report no conflicts of interest in this work.

\section{References}

1. Pearson RC, Goheen AC. Compendium of Grape Diseases. St Paul: The American Phytopathological Society; 1988.

2. Elad Y, Williamson B, Tudzynski P, Delen N. Botrytis: Biology, Pathology and Control. Dordrecht: Kluwer Academic Press; 2004.

3. Williamson B, Tudzynski B, Tudzynski P, Van Kan JAL. Botrytis cinerea: the cause of grey mould disease. Mol Plant Pathol. 2007;8:561-580.

4. Gasser F, Berg G. Organic versus conventional agriculture: a review from a microorganism's point of view. Cur Trends Microbiol. 2012;7:41-52.

5. Trioli G, Hofmann U. ORWINE: Code of Good Organic Viticulture and Wine-Making. Hofmann U, editor. Oppenheim: ECOVIN- Federal Association of Organic Wine-Producer; 2009.

6. Pietrzak U, McPhail DC. Copper accumulation, distribution and fractionation in vineyard soils of Victoria, Australia. Geoderma. 2004; 122:151-166.

7. Berg G. Plant-microbe interactions promoting plant growth and health: perspectives for controlled use of microorganisms in agriculture. Appl Microbiol Biotechnol. 2009;84:11-18.

8. Lugtenberg B, Kamilova F. Plant-growth-promoting rhizobacteria. Annu Rev Microbiol. 2009;63:541-556.

9. Compant S, Duffy B, Nowak J, Clement C, Barka EA. Use of plant growth-promoting bacteria for biocontrol of plant diseases: principles, mechanisms of action, and future prospects. Appl Environ Microbiol. 2005;71:4951-4959.

10. Zachow C, Fatehi JM, Tilcher R, Berg G. Strain-specific colonization pattern of Rhizoctonia antagonists in the root system of sugar beet. FEMS Microbiol Ecol. 2010;74:124-135.

11. Schmid F, Berg G. Grapevine-associated microorganisms: antagonistic potential towards Botrytis cinerea varies between habitats, cultivation methods and grapevine species. In: Elad Y, Maurhofer M, Keel C, Gessler C, Duffy B, editors. IOBC/WPRS bulletin. Proceedings of the IOBC/WPRS Working Group "Integrated Control of Plant Pathogens"; September 9-12, 2008; Interlaken, Switzerland. 2009;43:354-451.

12. Schmid F, Moser G, Müller M, Berg G. Functional and structural microbial diversity in organic and conventional viticulture: organic farming benefits natural biocontrol agents. Appl Environ Microbiol. 2011;77:2188-2191

13. Coutinho TA, Venter SN. Pantoea ananatis: an unconventional plant pathogen. Mol Plant Pathol. 2009;10:325-335.

14. Beattie GA, Lindow SE. Bacterial colonization of leaves: a spectrum of strategies. Phytopathology. 1999;89:353-359.

15. Kang SH, Cho HS, Cheong H, Ryu CM, Kim JF, Park SH. Two bacterial entophytes eliciting both plant growth promotion and plant defence on pepper (Capsicum annuum L.). J Microbiol Biotechnol. 2007; 17:96-103.

16. Torres R, Teixido N, Usall J, Abadias M, Vinas I. Post-harvest control of Penicillium expansum on pome fruits by the bacterium Pantoea ananatis CPA-3. J Horticult Science Biotechnol. 2005;80:75-81.

17. Chernin L, Ismailov Z, Haran S, Chet I. Chitinolytic Enterobacter agglomerans antagonistic to fungal plant pathogens. Appl Environ Microbiol. 1995;61:1720-1726.

18. Rezzonico F, Smits TH, Montesinos E, Frey JE, Duffy B. Genotypic comparison of Pantoea agglomerans plant and clinical strains. BMC Microbiol. 2009;9:204.

19. DSMZ [homepage on the Internet]. http://www.dsmz.de/. Leibniz institute DSMZ-German collection of microorganisms and cell cultures. Available from: http://www.dsmz.de/. Accessed October 19, 2011.

20. De Baere T, Verhelst R, Labit C, et al. Bacteremic infection with Pantoea ananatis. J Clin Microbiol. 2004;42:4393-4395.

21. Edwards SG, Seddon B. Selective media for the specific isolation and enumeration of Botrytis cinerea conidia. Lett Appl Microbiol. 2002;32: 63-66.
22. Gachon C, Saindrenan P. Real-time PCR monitoring of fungal development in Arabidopsis thaliana infected by Alternaria brassicicola and Botrytis cinerea. Plant Physiol Biochem. 2004;42:367-371.

23. McClean KH, Winson MK, Fish L, et al. Quorum sensing and Chromobacterium violaceum: exploitation of violacein production and inhibition for the detection of N-acylhomoserine lactones. Microbiology. 1997; 143:3703-3711

24. Sarwar M, Kremer RJ. Determination of bacterially derived auxins using a microplate method. Lett Appl Microbiol. 1985;20:282-285.

25. Rasche F, Velvis H, Zachow C, Berg G, Van Elsas JD, Sessitsch A. Impact of transgenic potatoes expressing anti-bacterial agents on bacterial endophytes is comparable with the effects of plant genotype, soil type and pathogen infection. $J$ Appl Ecol. 2006;43:555-566.

26. Berg G, Zachow C, Lottmann J, Götz M, Costa R, Smalla K. Impact of plant species and site on rhizosphere-associated fungi antagonistic to Verticillium dahliae Kleb. Appl Environ Microbiol. 2005;71: 4203-4213.

27. Winkelmann G, Lupp R, Jung G. Herbicolins - new peptide antibiotics from Erwinia herbicola. J Antibiot. 1980;33:353-358.

28. Rademaker JLW, De Bruijn FJ. Characterization and classification of microbes by REP-PCR genomic fingerprinting and computer-assisted pattern analysis. In: Caetano-Anollés G, Gresshoff PM, editors. DNA Markers: Protocols, Applications and Overviews. New York: Wiley; 1997.

29. Berg G, Krechel A, Ditz M, Sikora RA, Ulrich A, Hallmann J. Endophytic and ectophytic potato-associated bacterial communities differ in structure and antagonistic function against plant pathogenic fungi. FEMS Microbiol Ecol. 2005;51:215-229.

30. Bonaterra A, Mari M, Casalini L, Montesinos E. Biological control of Monilinia laxa and Rhizopus stolonifer in postharvest of stone fruit by Pantoea agglomerans EPS125 and putative mechanisms of antagonism. Int J Food Microbiol. 2003;84:93-104.

31. Brady SF, Wright SAI, Lee JC, et al. Pantocin B, an antibiotic from Erwinia herbicola discovered by heterologous expression of cloned genes. J Am Chem Soc. 1999;121:11912-11913.

32. Wright SAI, Zumoff CH, Schneider L, Beer SV. Pantoea agglomerans strain EH318 produces two antibiotics that inhibit Erwinia amylovora in vitro. Appl Environ Microbiol. 2001;67:284-292.

33. Ishimaru CA, Klos EJ, Brubaker RR. Multiple antibiotic production by Erwinia herbicola. Phytopathology. 1988;78:746-750.

34. Vanneste JL, Yu J, Beer SV. Role of antibiotic production by Erwinia herbicola Eh252 in biological control of Erwinia amylovora. J Bacteriol. 1992;174:2785-2796.

35. Greiner M, Winkelmann G. Fermentation and isolation of herbicolin A, a peptide antibiotic produced by Erwinia herbicola strain A111. Appl Microbiol Biotechnol. 1991;34:565-569.

36. Russell JB, Diez-Gonzalez F. The effects of fermentation acids on bacterial growth. Adv Microb Physiol. 1998;39:205-234.

37. Stratford M, Anslow PA. Evidence that sorbic acid does not inhibit yeast as a classic 'weak acid preservative'. Lett Appl Microbiol. 1998; 27:203-206

38. Roe AJ, O'Byrne C, McLaggan D, Booth IR. Inhibition of Escherichia coli growth by acetic acid: a problem with methionine biosynthesis and homocysteine toxicity. Microbiology. 2002;148(Pt 7): $2215-2222$

39. Ron EZ, Davis BD. Growth rate of Escherichia coli at elevated temperatures: limitation by methionine. J Bacteriol. 1971;107:391-396.

40. Gitaitis RD, Gay JD. First report of a leaf blight, seed stalk rot, and bulb decay of onion by Pantoea ananas in Georgia. Plant Dis. 1997;81:1096-1096.

41. Vantomme R, Mergaert J, Verdonck L, De Ley J. Antagonistic effect in vitro of Erwinia uredovora LMG 2678 against some other bacteria. J Phytopathol. 1989;124:372-376.

42. Sabaratnam S, Beattie GA. Differences between Pseudomonas syringae pv. syringae B728a and Pantoea agglomerans BRT98 in epiphytic and endophytic colonization of leaves. Appl Environ Microbiol. 2003;69:1220-1228. 
International Journal of Wine Research

Dovepress

\section{Publish your work in this journal}

The International Journal of Wine Research is an international, peer-reviewed open-access, online journal focusing on all scientific aspects of wine, including: vine growing; wine elaboration; human interaction with wine; and health aspects of wine. The journal provides an open access platform for the reporting

of evidence based studies on these topics. The manuscript management system is completely online and includes a very quick and fair peer-review system, which is all easy to use. Visit http://www.dovepress.com/testimonials.php to read real quotes from some of our published authors.

Submit your manuscript here: http://www.dovepress.com/international-journal-of-wine-research-journalisease-journal 